the 2 cohorts. The proportion of pSS NHLs patients with MALT lymphomas and $>1$ involved sites was significantly higher in cohort (A) compared to (UP) cohort [25/51, (49\%) vs 5/40 (12.5\%\%), $\mathrm{p}=0,0003)$ ] while extranodal localization of DLBC lymphomas was less frequent in Greek compared to Italian patients [2/12 (16.7\%) and 4/10 (40\%) respectively]. No significant differences were observed regarding anti-Ro/SSA, anti-La/ SSB, rheumatoid factors (RF) or history of parotid gland enlargement. Interestingly, no significant difference was also observed in the frequencies of serum cryoglobulinemia (without vasculitis) and C4 hypocomplementemia. Importantly, cryoglobulinemic skin vasculitis was significantly more frequent in cohort (A) than in cohort (UP) $[33 / 77$ (42,9\%) vs $12 / 63$ $(19,0 \%) \quad p=0,0027$ ] as well as bone marrow involvement by lymphoma [21/77 (27.2\%) vs $4 / 63(6.3 \%)$ respectively, $p=0,0015]$.

Conclusion: The similar lymphoma histologic subtypes, coupled with the differences in the frequency of cryoglobulinemic skin vasculitis and bone marrow involvement by lymphoma between Greek and Italian patients, suggest potential diversities in genetic background, environmental factors, disease progression and pathologic pathways in different cohorts, offering novel perspectives to study the biology of SS associated lymphomagenesis.

Disclosure of Interests: Andreas Goules: None declared, Chiara Baldini: None declared, Saviana Gandolfo: None declared, Aristea Papageorgiou: None declared, Dimitris Ziogas: None declared, Francesco Ferro: None declared, Valentina Donati: None declared, Cathryn Scott: None declared, Salvatore De Vita Grant/research support from: Roche, Pfizer, Abbvie, Novartis, BMS, MSD, Celgene, Janssen, Consultant for: Roche, Michael Voulgarelis: None declared, Athanasios Tzioufas Grant/research support from: ABBVIE, PFIZER, AMGEN, NOVARTIS, GSK

DOI: 10.1136/annrheumdis-2019-eular.5638

\section{SAT0191 LOW SOCIOECONOMIC STATUS AND HEALTH RELATED QUALITY OF LIFE IN PATIENTS WITH SYSTEMIC LUPUS ERYTHEMATOSUS}

Sebastian Herrera ${ }^{1}$, Juan Camilo Diaz-Coronado ${ }^{1,2}$, Deicy Hernandez ${ }^{1}$, Laura Betancur-Vasquez ${ }^{2}$, Ricardo Pineda.Tamayo ${ }^{1} .{ }^{1}$ Grupo de informacion clinica, Artmedica, Antioquia, Medellin, Colombia; ${ }^{2}$ Departamento medicina interna, Universidad CES, Medellin, Colombia

Background: Socioeconomic factors have been considered as possible confounding factors in the attribution of greater damage accrual in AfroCaribbean and Hispanic patients with Systemic lupus erythematosus
(SLE). Patients with SLE often experience long-term morbidity that can adversely affect their health-related quality of life (HRQoL)

Objectives: To analyze the relation between socioeconomic status, damage accrual and HRQoL

Methods: Analytic study in a cohort of SLE patients that were closely monitored in an autoimmunity program in Colombia. We stratified patients with damage (SDI $\geq 1)$ and no damage (SDI <1) and according to socioeconomic status as a surrogate value for economic income with dichotomization in low and medium/high income. We performed a non-parametric analysis of related simples of Wilcoxon in each of the dimensions of quality of life in EuroQoL $5 d$

Results: We analyzed 400 Colombian patients. Baseline median age was 49 years (15 IQR) with median age at diagnosis and disease duration of 37 years (17 IQR) and 9 years (13 IQR) respectively. There were $94 \%$ female patients and $17.3 \%$ late onset SLE. Most frequent clinical manifestations were hematological (82.8\%), mucocutaneous (75.3\%) and nephritis $(33.8 \%)$. Only $4.5 \%$ had neurological involvement. The mean SLEDA were 1.18 and 0.65 at first and second measurement respectively, in the first measurement $97.1 \%$ of the patients had a SLEDAl $\leq 4$. The mean SDI was 0.7275 at first measurement and 0.985 at the second measurement. When comparing the intervention in patients with $\mathrm{SDI} \geq 1$ there was a significative improvement in the Quotidian Activities, Pain/Discomfort, Anxiety/Depression domains, independent of economic income. In patients with medium-high income there was also a significative improvement in the mobility and personal care domains. In the no-damage groups there was only a positive impact in the Anxiety/Depression domain in a statistically significant manner, and the medium-high income subgroup had improvement in the Pain/Discomfort domain. We didn't find other statistically differences in the other domains. Low economic income seems to exert a negative influence in the different $H R Q$ oL domains with independence regarding treatment strategy, specially in patients with no damage accrual. In patients with higher income and damage accrual the opposite seems to appear, which could be related with a better ability or resources to cope with the consequences of the disease

Conclusion: In Colombian patients with SLE, socioeconomic status (as a reflection of income) might be related with HRQoL. This relationship could be influenced by damage accrual

\section{REFERENCE}

[1] Panopalis P, Petri M, Manzi S, Isenberg DA, Gordon C, Senecal JL, et al, and the Tri-Nation Study Group. The systemic lupus erythematosus TriNation study: cumulative indirect costs. Arthritis Rheum 2007;57:64-70

Disclosure of Interests: None declared

DOI: 10.1136/annrheumdis-2019-eular.6528

\begin{tabular}{|c|c|c|c|c|c|c|c|c|c|c|c|c|}
\hline & \multicolumn{6}{|c|}{ Damage present } & \multicolumn{6}{|c|}{ Damage absent } \\
\hline & \multicolumn{2}{|l|}{ Low incoming } & & \multicolumn{3}{|c|}{ Mid -high incoming } & \multicolumn{4}{|c|}{ Low incoming } & \multicolumn{2}{|c|}{ Mid -high incoming } \\
\hline & $\begin{array}{l}\text { Initial } \\
(\%)\end{array}$ & $\begin{array}{c}\text { Final } \\
(\%)\end{array}$ & p Value ${ }^{\dagger}$ & $\begin{array}{c}\text { Initial } \\
(\%)\end{array}$ & $\begin{array}{c}\text { Final } \\
(\%)\end{array}$ & p Value ${ }^{\dagger}$ & $\begin{array}{c}\text { Initial } \\
(\%)\end{array}$ & $\begin{array}{c}\text { Final } \\
(\%)\end{array}$ & p Value ${ }^{\dagger}$ & $\begin{array}{c}\text { Initial } \\
(\%)\end{array}$ & $\begin{array}{c}\text { Final } \\
(\%)\end{array}$ & p Value \\
\hline Mobility & 51 & 55 & 0,4 & 56,6 & 72,3 & 0,004 & 54,3 & 60,3 & 0,35 & 59,2 & 68 & 0,13 \\
\hline 1 & 48 & 45 & & 42,2 & 27,7 & & 44,8 & 37,9 & & 40,8 & 32 & \\
\hline 2 & 1 & 0 & & 1,2 & 0 & & 0,9 & 1,7 & & 0 & 0 & \\
\hline \multicolumn{13}{|l|}{3} \\
\hline Personal Care & 72 & 76 & 0,35 & 73,5 & 84,3 & 0,016 & 72,4 & 76,7 & 0,5 & 78,8 & 79,8 & 0,85 \\
\hline 1 & 27,1 & 23 & & 24,1 & 15,7 & & 26,7 & 21,6 & & 21,2 & 20,2 & \\
\hline 2 & 1 & 0 & & 2,4 & 0 & & 0,9 & 1,7 & & 0 & 0 & \\
\hline \multicolumn{13}{|l|}{3} \\
\hline Quotidian & 51,5 & 67 & 0,005 & 59,8 & 73,2 & 0,03 & 60,3 & 62,9 & 0,7 & 65 & 68,9 & 0,5 \\
\hline Activities & 44,3 & 33 & & 36,6 & 25,6 & & 38,8 & 31,9 & & 34 & 30,1 & \\
\hline 1 & 4,1 & 0 & & 3,7 & 1,2 & & 0,9 & 5,2 & & 1 & 1 & \\
\hline \multicolumn{13}{|l|}{2} \\
\hline \multicolumn{13}{|l|}{3} \\
\hline Pain/Discomfort & 34 & 38,1 & 0,008 & 30,1 & 44,6 & 0,003 & 37,9 & 30,2 & 0,5 & 23,1 & 40,4 & 0,002 \\
\hline 1 & 39,2 & 53,6 & & 50,6 & 49,4 & & 41,4 & 52,6 & & 53,8 & 47,1 & \\
\hline 2 & 26,8 & 8,2 & & 19,3 & 6 & & 20,7 & 17,2 & & 23,1 & 12,5 & \\
\hline \multicolumn{13}{|c|}{3} \\
\hline Anxiety/ & 51 & 70,8 & 0,001 & 61 & 79,3 & 0,001 & 51,3 & 66,4 & 0,01 & 53,9 & 73,5 & 0,001 \\
\hline Depression & 32,3 & 22 & & 26,8 & 18,3 & & 35,4 & 27,4 & & 32,4 & 23,5 & \\
\hline 1 & 16,7 & 7,2 & & 12,2 & 2,4 & & 13,3 & 6,2 & & 13,7 & 2,9 & \\
\hline \multicolumn{13}{|c|}{2} \\
\hline 3 & & & & & & & & & & & & \\
\hline
\end{tabular}

